\title{
Running Head: Stress, Cortisol, and Social Hierarchy
}

\section{In press at Current Opinion in Psychology}

\author{
Stress, Cortisol, and Social Hierarchy \\ Gary D. Sherman* \\ Stony Brook University \\ Pranjal H. Mehta* \\ University College London
}

\author{
*Corresponding Authors \\ Gary D. Sherman \\ Stony Brook University \\ 204 Harriman Hall \\ Stony Brook, NY 11794 USA \\ Gary.Sherman@stonybrook.edu \\ Pranjal H. Mehta \\ Department of Experimental Psychology \\ University College London \\ 26 Bedford Way \\ London WC1H 0AP United Kingdom \\ pranj.mehta@ucl.ac.uk
}




\begin{abstract}
We review the literature on the relationships between cortisol, stress and various forms of social status, concluding that cortisol (and stress) is typically elevated when one chronically lacks, or may soon lose, status. Moreover, cortisol is lower when status is higher as long as that status is stable, enhances one's sense of control, and does not also substantially increase one's responsibilities. Because cortisol is both an output (stress indicator) and input (cause of behavioral inhibition), this low cortisol may be both a cause and consequence of stable status. Altogether, the cortisol-status relationship depends not just on one's status but on what that status means for the individual (e.g., How frequent and severe are stressors? Does one feel a sense of control? Does one need to be vigilant and deferential?).
\end{abstract}

Keywords: stress; cortisol; status; power; social hierarchy 


\section{Stress, Cortisol, and Social Hierarchy}

In the 1980's, primate researchers, such as Sapolsky and colleagues, started reporting an inverse relationship between adrenal stress hormones (glucocorticoids) and social rank in nonhuman primates, at least in stable hierarchies $[1,2,3]$. Ever since, the relationships among stress, cortisol (the primary glucocorticoid in humans), and social hierarchy, and whether these relationships hold among humans, have drawn significant scientific interest. We review the most recent literature bearing on these relationships. We focus on the important role of the psychological sense of control and the moderation of the cortisol-status relationship by hierarchy stability. We conclude that cortisol is typically elevated when one chronically lacks, or may soon lose, status [4] and that cortisol will be lower when status is higher as long as that status is stable, enhances one's sense of control, and does not substantially increase one's responsibilities as well (as often happens in organizational hierarchies).

\section{Cortisol as Input and Output}

Before reviewing cortisol's relationship to social hierarchy, we briefly summarize what higher (vs. lower) cortisol could signify, psychologically and physiologically.

1.1. Cortisol as output: cortisol as an indicator of stress. To stress researchers, cortisol is an important outcome variable that is influenced by both acute and chronic stressors. Controllability has emerged as a key factor predicting the cortisol response to stress, with uncontrollable (vs. controllable) acute stressors eliciting a stronger cortisol response [5] and uncontrollable (vs. controllable) chronic stressors predicting the pattern of cortisol across the day [6]. The typical diurnal pattern consists of relatively high levels in the morning (with an immediate spike in cortisol in the first 45 minutes post-awakening) followed by a steady decline 
throughout the day [7]. Chronic, uncontrollable stressors tend to be associated with a flatter diurnal slope [6], a pattern linked to increased cardiovascular mortality risk [8].

1.2. Cortisol as input: cortisol and behavioral inhibition. Cortisol is more than just a hormonal readout of psychological or physiological stress. Once released, it has its own effects on behavior. One of these effects is behavioral inhibition, which is the tendency to withdraw from (rather than approach) novel and unfamiliar stimuli [9]. Behavioral inhibition has been widely studied by developmental psychologists examining how children respond to challenging or unfamiliar situations $[10,11]$. Among the biological bases of behavioral inhibition, cortisol seems to play an important role, with high cortisol predicting behavioral inhibition (e.g., avoidance of an unfamiliar child) among children [11, 12, cf. 13].

That cortisol predicts behavioral inhibition in unfamiliar or challenging contexts is consistent with the specific known effects of cortisol across species. For example, among rhesus monkeys, baseline cortisol predicts the duration of freezing behavior, a specific form of behavioral inhibition [14]. Speaking to cortisol's causal role in freezing, one study found that removal of the adrenal gland in rats - thereby blocking release of corticosterone (the primary glucocorticoid hormone in rats, analogous to cortisol in humans) —impaired defensive freezing behavior, which was subsequently restored by corticosterone administration [15]. Among adult humans, cortisol similarly predicts indicators of inhibition, such as post-error slowing, the tendency to slow down after making a mistake [16].

\section{The relationship between Status and Cortisol (and Stress)}

First, we consider recent evidence regarding main effects, that is, tests of the bivariate relationship between various indicators of social status, power, or dominance, and measures of either psychological stress or cortisol. We focus on several forms of status, including status in an 
organizational hierarchy, socioeconomic status (SES), and one's position within their social networks.

2.1. Lacking status in an organizational hierarchy. Several recent investigations have studied status and stress in the workplace, examining individuals at various levels of status, power, and authority within their organizations. For example, a study of government and military leaders found that higher-level leaders (i.e., those with greater authority and more subordinates) had lower cortisol levels (and less anxiety) than lower-level leaders [17], a relationship that was statistically mediated by the higher-level leaders' greater sense of control. A study of nongovernmental organizations in Portugal [18] found the inverse pattern: that those lower in the hierarchy had lower cortisol. Although a greater sense of control was, on average, associated with lower cortisol, this relationship reversed at lower levels of the hierarchy (for middle managers and non-leaders). Thus, the stress-buffering benefits of control were only experienced by those at the top of the hierarchy.

A separate study of managers in various organizations in Portugal used fuzzy-set qualitative comparative analysis to test the necessary and sufficient conditions for stress (i.e., anxiety) in organizational hierarchies $\left[19^{*}\right]$. The results revealed there were multiple recipes for stress and that one's position in the hierarchy was not a sufficient condition for either the presence or absence of stress. Moreover, sense of control proved critical: its absence was almost always necessary for high stress and its presence was necessary for low stress (i.e., sense of control was present in all "recipes" for low stress).

A recent investigation examined these relationships in four samples (Switzerland, United States, China, and Japan), measuring leadership/supervisory role, job demands, job control, and both psychological and physiological well-being [20**]. Occupying a supervisory position (an 
ostensibly high-status position) was associated with greater job control and greater job demands. The former was positively — and the latter negatively — associated with several indices of wellbeing. In each of the three samples for which cortisol was measured (US, China, and Japan), there was a non-significant total effect from leadership role to cortisol but a significant positive indirect effect via job demands_-leadership role was associated with greater job demands which predicted higher cortisol. These results highlight the complexities of assessing the cortisol-status relationship in organizational hierarchies. In informal social hierarchies, greater social status often confers greater social benefits without imposing greater demands or responsibility. In formal organizational hierarchies, however, greater status typically confers both greater control and greater responsibility. Thus, the overall effect of status on cortisol, stress, and well-being may depend on the relative contributions of these two countervailing factors.

2.2. Lacking status in one's social network. Several recent studies have used social network analysis to examine the relationship between hormones and several features of one's social network. These studies have found that individuals with higher cortisol tend to be less gregarious (i.e., have fewer outgoing friendship ties; $\left[21,22,23^{*}\right]$ ) and tend to occupy less influential and central positions in their social networks $\left[23^{*}\right]$ ). Similarly, a recent study found that children (5-12 years old) with higher baseline cortisol reported a lower density of friendships [24].

2.3. Lacking SES. Social class has long been identified as a reliable predictor of health and well-being. For example, in the Whitehall studies, a large-scale investigation of British civil servants, employment grade (a facet of SES) was found to be inversely related to several objective health outcomes (e.g., indicators of cardiovascular health) and self-perceived health status [25]. Several more recent studies have found that lower SES individuals (or those who had 
low childhood SES) tend to have a stronger inflammatory response (e.g., pro-inflammatory cytokines) to social stress $[26,27,28,29]$, which can be detrimental to health if chronic [30]. The relationship between SES and well-being appears to be due to several factors associated with low SES such as diminished job control [31] and diminished financial security [32].

Research on SES and cortisol has focused on diurnal cortisol (i.e., the shape of the cortisol response across a full day), finding that low-SES individuals show the pattern typically associated with chronic uncontrollable stressors - a flatter diurnal slope [6, 33]. This pattern, which has been found to mediate the relationship between SES and negative health symptoms [34*], is moderated by sense of control: The indirect effect only emerges when control is low [34*]. This study found that for low-SES individuals who felt a sense of control, SES was not associated with a flatter cortisol slope. As a result, the relationship between SES and negative physical symptoms was significantly diminished for these individuals.

2.4. Other evidence. A recent study found that women with higher facial dominance (according to observer ratings) had lower baseline cortisol [35]. If dominant-looking women are more likely to attain social status, this relationship may reflect the stress-buffering benefits of social status (e.g., greater control). Although the opposite causal direction-lower cortisol causing facial dominance - is unlikely, the authors suggest that a third variable, such as stress during development, could affect both facial morphology and HPA activity.

\section{The Moderating Role of Hierarchy Stability}

In the research on cortisol and social status among non-human primates, it has been long observed that the negative relationship between the two variables typically only holds when the social hierarchy is stable [36]. Recent research has shown this to be the case among humans as well. In a study of risk taking [4], it was found that the effect of social power on risk taking 
depended on the stability of the hierarchy: stable powerlessness and unstable power were associated with preferences for greater risk due to the greater stress associated with these two states compared to unstable powerlessness and stable power. This pattern suggests the stresspower link is moderated by hierarchy stability—power only confers lower stress when it is stable.

A study of Chinese managers found that managers who occupied higher-level positions within their organizational hierarchy reported less work stress but only if they also perceived their position as stable [37]. The causal role of hierarchy stability on the status-cortisol link was recently tested $\left[38^{* *}\right]$ by experimentally manipulating both status and the perceived stability of that status to examine how these factors influence cortisol reactivity to an acute social-evaluative stressor (a public speech). Participants with unstable high status had greater cortisol reactivity and slower recovery than those who had stable high status. Participants' feelings of control showed a comparable pattern: high status only increased feelings of control when that status was stable. Another recent study [39] similarly manipulated both status and stability before participants performed a task (a dyadic task), finding a significant interaction in predicting greater total peripheral resistance (TPR: a cardiovascular response consistent with a threat response [40]). Increases in TPR from baseline were greatest among the stable powerless and the unstable powerful suggesting that these states induced the strongest threat response. These findings are consistent with recent research suggesting that the typical behavioral effects of power and status, such as greater approach behavior [41], often do not emerge when power is unstable [42] or perceived as illegitimate [43].

\section{Summary and Integration}


The above review of recent research suggests that the role of cortisol in social hierarchy is multifaceted, consistent with cortisol's multifaceted, multiply-determined nature. In some contexts, such as SES, changes in cortisol (e.g., blunted diurnal response) may reflect the cumulative effect of chronic stressors. In other contexts, such as organizational hierarchies, elevated cortisol may reflect diminished control and/or greater job demands. Importantly, for thinking about cortisol as a consequence of status, it is not status or power per se that is critical but the sense of control that status often, but not always, affords. Unstable power and status, for example, are not associated with lower cortisol/stress $\left[37,38^{* *}\right]$ or greater approach motivation [41], instead triggering a threat response [39] typically observed among the powerless in stable hierarchies.

In light of the behavioral effects of cortisol (i.e., behavioral inhibition), elevated cortisol among individuals with low-status (in stable hierarchies) may underlie deferential or submissive behavior [16]. That is, cortisol may help low-status individuals navigate their social worlds effectively (being vigilant and acting submissively to diffuse and minimize the potential aggression of high-status individuals). This possibility is consistent with an observation of Eberhart and colleagues [1] in their study of talapoin monkey hierarchies. They found that the lowest-ranking members of the social group had elevated cortisol when they were housed with other monkeys but not when they were isolated from the group. The elevated cortisol of the lowranking monkeys when housed with other monkeys may reflect the behavioral demands of interacting with high-ranking individuals.

Additionally, the cortisol-inhibition link suggests that lower cortisol among high-status individuals (in organizational hierarchies and social networks) may sometimes be a cause of status. Because low cortisol is associated with behavioral disinhibition $[11,12]$, which in turn is 
associated with behaviors, such as assertiveness and decisiveness that may affect leader perceptions [44], one's level of cortisol may affect whether one acts in a behaviorally disinhibited way (i.e., decisively and assertively) and whether one ultimately attains status (e.g., emerges as a leader) in the eyes of one's peers.

\section{Future Directions}

In this article, we reviewed recent research on the association between status and cortisol (and stress) in humans. Here we discuss three key directions for future work.

5.1. Longitudinal studies. Few studies in humans have tracked within-person changes in cortisol, stress, and status over time. New longitudinal studies can provide insight into causal pathways and psychological mechanisms. For example, it is likely that the status-cortisol relationship changes over time due to naturally occurring changes in the hierarchy, such as shifts in the stability of the hierarchy, changes in job responsibilities and workload, promotions and demotions, or the restructuring of hierarchies (e.g. corporate mergers or acquisitions). Given the current review, these longitudinal studies may benefit from measuring sense of control and behavioral inhibition. For example, do individuals who lack status interact regularly with higherranked individuals and if so, do they feel compelled to show deference and remain vigilant for displays of dominance or aggression? By addressing these questions, this future research could capture not only an individual's objective status but also the meaning and implications of this status for the individual. Perhaps most important, by tracking within-person changes over time, longitudinal studies should help determine the extent to which cortisol acts as an input (i.e., cause) and/or output (i.e., consequence) of social status.

5.2. Stress contagion in social hierarchies. Recent research on status and cortisol has focused primarily on associations between one's own status and one's own stress and cortisol 
levels. Some work suggests that stress can be "contagious", transmitting from one person to the other in social interactions [45]. In social hierarchies, it is possible that leaders and followers dynamically influence each other's cortisol levels. Yet cortisol contagion in social hierarchies remains largely unexplored.

5.3. Testosterone, cortisol, and status. Testosterone is a reproductive hormone released as an end product of the hypothalamic-pituitary-gonadal axis in both males and females. Recent work suggests that this hormone influences the motivation to gain status and moderates the relationship between cortisol and status: cortisol is negatively related to status especially when testosterone levels are high [46]. That is, the combination of low cortisol and high testosterone is related to high status, whereas the combination of high cortisol and high testosterone is related to low status. The cortisol-testosterone interaction predicts markers of status in hierarchies of students, executives, and athletes (e.g., Olympic athletes), and seems to hold in both males and females [23, 47-50].

These studies linking the cortisol-testosterone interaction to status have relied on correlational designs. New experimental research will be needed to understand causality. Does an increase in testosterone and a decrease in cortisol cause individuals to attain higher status in the hierarchy, does higher status in a stable hierarchy cause cortisol levels to decrease and testosterone levels to increase, or migh both causal pathways operate dynamically? The psychological mechanism that explains this dual-hormone interaction on status is also unknown. Researchers have theorized that high testosterone increases the drive for status and low cortisol enhances behavioral disinhibition, which together increase an individual's tendency to attain high status $[47,49]$. An alternative hypothesis is that a stable position of high status increases 
one's sense of control, which in turn causes cortisol levels to drop and testosterone levels to rise over time. Direct tests of these hypotheses will require additional work.

\section{Conclusion}

Altogether, as Sapolsky remarked in the study of glucocorticoids in primate hierarchies [36], cortisol levels (and stress) will depend not just on an individual's status in the hierarchy (subordinance or dominance) but on what that status means for the individual (e.g., How frequent and severe are stressors? Does one feel a sense of control? Does one need to be vigilant and deferential?). 
Stress, Cortisol, and Social Hierarchy 13

Funding: This work was supported by the National Science Foundation [grant number 1451848]. 


\section{References}

1. Eberhart JA, Keverne EB, Meller RE: Social influences on circulating levels of cortisol and prolactinin male talapoin monkeys. Physiol Behav 1983, 30: 361-369.

2. Sapolsky RM: Hypercortisolism among socially subordinates wild baboons originates at the CNS level. Arch Gen Psychiat 1989, 46: 1047-1051.

3. Yodyingyuad U, De La Riva C, Abbott DH, Herbert J, Keverne EB: Relationship between dominance hierarchy, cerebrospinal fluid levels of amine transmitter metabolites (5-hydroxyindole acetic acid and homovanillic acid) and plasma cortisol in monkeys. Neuroscience 1985, 16: 851-858.

4. Jordan J, Sivanathan N, Galinsky A: Something to lose and nothing to gain: The role of stress in the interactive effect of power and stability on risk taking. Admin Sci Quarterly 2011, 56: 530-558.

5. Dickerson SS, Kemeny ME: Acute stressors and cortisol responses: A theoretical integration and synthesis of laboratory research. Psychol Bull 2004, 130: 355-391.

6. Miller GE, Chen E, Zhou ES (2007) If it goes up, must it come down? Chronic stress and the hypothalamic-pituitary-adrenocortical axis in humans. Psychol Bull 2007, 133: $25-45$.

7. Posener JA, Schildkraut JJ, Samson JA, Schatzberg AF: Diurnal variation of plasma cortisol and homovanillic acid in healthy subjects. Psychoneuroendocrino 1996, 21: $33-38$.

8. Kumari M, Shipley M, Stafford M, Kivimaki M: Association of diurnal patterns in salivary cortisol with all-cause and cardiovascular mortality: findings from the Whitehall II study. J Clin Endocr Metab 2011, 96: 1478-1485. 
9. Garcia Coll C, Kagan J, Reznick JS: Behavioral inhibition in young children. Child Dev 1984, 55: 1005-1019.

10. Fox NA, Henderson HA, Marshall PJ, Nichols, KE, Ghera M: Behavioral inhibition: Linking biology and behavior within a developmental framework. Annu Rev Psychol 2005, 56: 235-262.

11. Kagan J, Reznick JS, Snidman N: The physiology and psychology of behavioral inhibition in children. Child Dev 1987, 58: 1459-1473.

12. Schmidt LA, Fox NA, Rubin KH, Sternberg EM, Gold PW, Smith CC, Schulkin J: Behavioral and neuroendocrine responses in shy children. Dev Psychobio 1997, 30: $127-140$

13. De Haan M, Gunnar MR, Tout K, Hart J, Stansbury K: Familiar and novel contexts yield different associations between cortisol and behavior among 2-year-old children. Dev Psychobio 1998, 33: 93-101.

14. Kalin NH, Shelton SE, Rickman M, Davidson RJ: Individual differences in freezing and cortisol in infant and mother rhesus monkeys. Beh Neurosci 1998, 112: 251-254.

15. Takahashi LK, Rubin WW: Corticosteroid induction of threat-induced behavioral inhibition in preweanling rats. Beh Neurosci 1993, 107: 860-866.

16. Tops M, Boksem MA: Cortisol involvement in mechanisms of behavioral inhibition. Psychophysiology 2011, 48: 723-732.

17. Sherman GD, Lee JJ, Cuddy AJ, Renshon J, Oveis C, Gross JJ, Lerner JS: Leadership is associated with lower levels of stress. P Natl Acad Sci USA 2012, 109: 17903-17907. 
18. Guedes MJ, Gonçalves HM, Gonçalves VDC, Patel PC: Lower on the totem pole: The influence of sense of control and trait anxiety on cortisol at lower hierarchical levels. Int J Stress Manage 2018, 25: 94-107.

19. * Guedes MJ, Gonçalves HM, da Conceição Gonçalves V: Stress at the top: myth or fact? Causal explanations from a fuzzy-set qualitative comparative analysis (fsQCA). Qual Quant 2017, 51: 2001-2017.

The first study to use qualitative comparative analysis to determine the different recipes for stress in a social hierarchy. In a sample of managers, the authors found that status was not a sufficient condition for either the presence of absence of stress. Sense of control was a key variable in nearly all recipes of high vs. low stress, with its absence being (almost) always necessary for high stress and its presence being necessary for low stress.

20. ** Li WD, Schaubroeck JM, Xie JL, Keller AC: Is being a leader a mixed blessing? A dual-pathway model linking leadership role occupancy to well-being. J Organ Behav 2018, 39: 971-989.

This study examined the dual contributions of job demands and job control to leader well-being, finding greater status in an organizational hierarchy is associated with outcomes - greater control and greater job demands - that have countervailing effects on stress and well-being.

21. Kornienko O, Clemans KH, Out D, Granger DA: Friendship network position and salivary cortisol levels. Soc Neurosci 2013, 8: 385-396.

22. Kornienko O, Clemans KH, Out D, Granger DA: Hormones, behavior, and social network analysis: Exploring associations between cortisol, testosterone, and network structure. Horm Behav 2014, 66: 534-544.

23. * Ponzi D, Zilioli S, Mehta PH, Maslov A, Watson NV: Social network centrality and hormones: The interaction of testosterone and cortisol. Psychoneuroendocrino 2016, 68: 6-13. 
This study examined the joint influence of cortisol and testosterone on one's centrality in their social network (in this case, the network was a male rugby club). Although the authors focused their discussion on the interaction of testosterone and cortisol, the main effects of cortisol are noteworthy for the current review. Individuals with lower cortisol were higher on the variable of betweenness, which reflects an individuals' influence in the group (the extent to which one is a "connector"). In addition to being connectors, lower-cortisol individuals were more popular (i.e., more incoming ties). Altogether, low cortisol was associated with having attained higher status (i.e., greater centrality and influence) in one's social network.

24. Ponzi D, Muehlenbein MP, Geary DC, Flinn MV: Cortisol, salivary alpha-amylase and children's perceptions of their social networks. Soc Neurosci 2016, 11: 164-174.

25. Marmot MG, Smith GD, Stansfeld S, Patel C, North F, Head J, White I, Brunner E, Feeney A: Health inequalities among British civil servants: the Whitehall II study. Lancet 1991, 337: 1387-1393.

26. Brydon L, Edwards S, Mohamed-Ali V, Steptoe A: Socioeconomic status and stressinduced increases in interleukin-6. Brain Behav Immun 2004, 18: 281-90.

27. Derry HM, Fagundes CP, Andridge R, Glaser R, Malarkey WB, Kiecolt-Glaser JK: Lower subjective social status exaggerates interleukin-6 responses to a laboratory stressor. Psychoneuroendocrino 2013, 38: 2676-2685.

28. Muscatell KA, Dedovic K, Slavich GM, Jarcho MR, Breen EC, Bower JE, Irwin MR, Eisenberger NI: Neural mechanisms linking social status and inflammatory responses to social stress. Soc Cogn Affect Neur 2016, 11: 915-922.

29. Miller GE, Chen E, Fok AK, Walker H, Lim A, Nicholls EF, Cole S, Kobor MS: Low early-life social class leaves a biological residue manifested by decreased glucocorticoid and increased proinflammatory signaling. P Natl Acad Sci USA 2009, 106: $14716-21$. 
30. Miller AH, Maletic V, Raison CL: Inflammation and its discontents: the role of cytokines in the pathophysiology of major depression. Biol Psychiat 2009, 65: 73241.

31. Bosma H, Marmot MG, Hemingway H, Nicholson AC, Brunner E, Stansfeld SA: Low job control and risk of coronary heart disease in Whitehall II (prospective cohort) study. BMJ-Brit Med J 1997, 314: 558-565.

32. Ferrie JE, Shipley MJ, Stansfeld SA, Smith GD, Marmot, MG: Future uncertainty and socioeconomic inequalities in health: the Whitehall II study. Soc Sci Med 2003, 57: $637-646$.

33. Hajat A, Diez-Roux A, Franklin TG, Seeman T, Shrager S, Ranjit N, Castro C, Watson, K, Sanchez B, Kirschbaum C: Socioeconomic and race/ethnic differences in daily salivary cortisol profiles: the multi-ethnic study of atherosclerosis. Psychoneuroendocrino 2010, 35: 932-943.

34. * Zilioli S, Imami L, Slatcher RB: Socioeconomic status, perceived control, diurnal cortisol, and physical symptoms: a moderated mediation model. Psychoneuroendocrino 2017, 75: 36-43.

This large-scale study found that that lower SES was associated with more negative health symptoms and that this relationship was statistically mediated by the flatter diurnal cortisol pattern observed among low-SES individuals. Moreover, for low-SES individuals who felt a sense of control, SES was not associated with a flatter cortisol slope and, therefore, the strength of the SES-health link was significantly weaker. This finding highlights the important role of the psychological sense of control in understanding the relationship between SES and health.

35. Gonzalez-Santoyo I, Wheatley JR, Welling LL, Cárdenas RA, Jimenez-Trejo F, Dawood K, Puts DA: The face of female dominance: Women with dominant faces have lower cortisol. Horm Behav 2015, 71, 16-21. 
36. Sapolsky RM: Social subordinance as a marker of hypercortisolism: Some unexpected subtleties. Ann NY Acad Sci 1995, 771: 626-639.

37. Feenstra S, Jordan J, Walter F, Yan J, Stoker JI: The hazard of teetering at the top and being tied to the bottom: The interactive relationship of power, stability, and social dominance orientation with work stress. Appl Psychol-Int Rev 2017, 66: 653-673.

38. ** Knight EL, Mehta PH: Hierarchy stability moderates the effect of status on stress and performance in humans. P Natl Acad Sci USA 2017 114: 78-83.

The first study to experimentally test the causal role of hierarchy stability on the effect of status on the cortisol response to an acute stressor. The authors experimentally manipulated both status and the perceived stability of that status before participants performed a socially stressful task (The Trier Social Stress test). The effect of status on cortisol reactivity and recovery was moderated by the perceived stability of status. Participants with stable status had lower cortisol reactivity and faster recovery than those who had unstable status. Likewise, status only increased participants' feelings of control when that status was stable.

39. Scheepers D, Roell C, Ellemers N: Unstable power threatens the powerful and challenges the powerless: Evidence from cardiovascular markers of motivation. Front Psychol 2015, 6: 720.

40. Mendes WB, Blascovich J, Lickel B, Hunter S: Challenge and threat during social interactions with White and Black men. Pers Soc Psychol B 2002, 28: 939-952.

41. Keltner D, Gruenfeld DH, Anderson C: Power, approach, and inhibition. Psychol Rev 2003, 110: 265-284.

42. Jury M, Quiamzade A, Darnon C, Mugny G: Higher and lower status individuals' performance goals: The role of hierarchy stability. Motiv Sci 2019, 5: 52-65.

43. Lammers J, Galinsky AD, Gordijn EH, Otten S: Illegitimacy moderates the effects of power on approach. Psychol Sci 2008, 19: 558-564. 
44. Judge TA, Bono JE, Ilies R, Gerhardt MW: Personality and leadership: a qualitative and quantitative review. J Appl Psychol 2002, 87: 765-780.

45. Waters, SF, West TV, Mendes WB: Stress contagion: Physiological covariation between mothers and infants. Psycho Sci 2014, 25: 934-942.

46. Dekkers TJ, van Rentergem JAA, Meijer B, Popma A, Wagemaker E, Huizenga HM: A meta-analytical evaluation of the dual-hormone hypothesis: Does cortisol moderate the relationship between testosterone and status, dominance, risk taking, aggression, and psychopathy? Neurosci Biobehav Rev 2019, 96: 250-271.

47. Mehta PH, Josephs RA: Testosterone and cortisol jointly regulate dominance: Evidence for a dual-hormone hypothesis. Horm Behav 2010, 58: 898-906.

48. Edwards DA, Casto KV: Women's intercollegiate athletic competition: cortisol, testosterone, and the dual-hormone hypothesis as it relates to status among teammates. Horm Behav 2013, 64: 153-160.

49. Sherman GD, Lerner JS, Josephs RA, Renshon J, Gross JJ: The interaction of testosterone and cortisol is associated with attained status in male executives. J Pers Soc Psychol 2016, 110: 921-929.

50. Casto KV, Hamilton DK, Edwards DA: Testosterone and Cortisol Interact to Predict Within-Team Social Status Hierarchy among Olympic-Level Women Athletes. Adaptive Human Behavior and Physiology 2019, 1-14. 